\title{
Detection and Mapping of QTLs Affecting Contents of Pharmaceutical Alkaloids in Leaf and Root of Catharanthus roseus
}

\author{
Swati Chaudhary $\cdot$ Richa Pandey $\cdot$ Vishakha Sharma • \\ Bhumi Nath Tripathi $\cdot$ Sushil Kumar
}

Received: 29 February 2012/ Accepted: 27 December 2012/Published online: 30 January 2013

(C) NAAS (National Academy of Agricultural Sciences) 2013

\begin{abstract}
Catharanthus roseus leaves and roots hyper-accumulate the terpenoid indole alkaloids, which are required for the economic production of pharmaceutical molecules vindoline (V), catharanthine (C), vinblastine (VB), vincristine (VC), ajmalicine (A) and serpentine (S). For developing marker-assisted selection (MAS) breeding in C. roseus, the objectives of the present study were: (a) To characterize variability and associations between six traits-V (VL), C (CL), VB + VC (VBL) contents of leaves and C (CR), A (AR) and S (SR) contents in roots, in a recombinant inbred line (RIL) population in two environments. (b) To identify and place quantitative trait loci (QTLs) associated with the traits on the map. The population of 191 RILs was found to segregate transgressively for all the six traits. The intra-organ correlations of leaf and root traits were positive and significant. The inter-organ traits were not correlated. All the traits except AR were highly heritable $\left(h^{2}=41-79 \%\right)$. A RIL population genetic map of 179 markers on 8 linkage groups (LGs) covering $1,786.5 \mathrm{cM}$ genetic distance was constructed. The RIL-generated genetic map led to identification of 20 QTLs for 6 traits $(5,4,1,4,2$, and 4 QTLs, respectively for CL, VL, VBL, CR, AR, and SR) by the use of single marker regression, simple interval mapping and composite interval mapping approaches. QTLs were detected only on 4 of the 8 LGs. QTL for the same or different traits were mapped in clusters or singularly. The results suggest that a combination of MAS and phenotypic selection offer possibilities of realizing simultaneous improvement in $\mathrm{C}$ and $\mathrm{V}$ accumulation in leaves and roots of $C$. roseus.
\end{abstract}

Keywords Composite interval mapping - Linkage map - Medicinal plant $\cdot$ Single marker analysis ·

Simple interval mapping $\cdot$ Terpenoid indole alkaloids

Electronic supplementary material The online version of this article (doi:10.1007/s40003-013-0050-1) contains supplementary material, which is available to authorized users.

S. Chaudhary $\cdot$ R. Pandey $\cdot$ V. Sharma $\cdot$ S. Kumar $(\bowtie)$

Genetical Genomics Laboratory, National Institute of Plant

Genome Research (NIPGR), Aruna Asaf Ali Marg, New Delhi

110067, India

e-mail: sushil2000_01@yahoo.co.in; s_kumar@nipgr.res.in

S. Chaudhary · B. N. Tripathi

Banasthali University, PO Banasthali Vidhyapeeth,

Rajasthan 304022, India

\section{Introduction}

The apocynaceous species Catharanthus roseus produces more than 130 terpenoid indole alkaloids (TIAs), including several useful as drugs, vinblastine (VB) and vincristine (VC) for cancer chemotherapies and ajmalicine (A) and serpentine (S) in the treatments of arterial hypertension and anxiety, respectively $[25,62,78,80]$. Some of the TIAs have been shown to provide protection to $C$. roseus against pests $[7,47,53,66]$. The highly valuable species specific $\mathrm{VB}$ and $\mathrm{VC}$ and their more effective synthetic analogs are semi-synthesized commercially from vindoline (V) and catharanthine $(\mathrm{C})$, the natural precursors of $\mathrm{VB}$ and $\mathrm{VC}$, purified from the leaf extracts of the cultivated $C$. roseus plants [30, 32, 65, 77]. The cost of production is high 
because the $\mathrm{V}, \mathrm{C}, \mathrm{VB}$, and $\mathrm{VC}$ accumulate in plant organs in very low concentrations $[15,50,51,58,64,74,78]$. The compounds $\mathrm{V}, \mathrm{VB}$, and $\mathrm{VC}$ have been totally synthesized but the processes are industrially inviable [31, 33, 84].

The progress in dissection of the biosynthetic pathway has shown that the process is highly complex and involves subpathways accomplished in various organelles of cells of different tissues in aerial organs and roots $[20,50,59,78$, 79]. Central intermediate of TIAs is strictosidine [2, 18, 20, 21] formed as condensate of the indolic precursor tryptamine derived from shikimate pathway [12, 29, 68] and the terpenoid secologanin precursor derived from combination of methyl erythritol phosphate-pathway and monoterpenesecoiridoid-pathway $[4,9,19,25,60]$. Cathenamine synthesized from strictosidine via several steps serves as the branch point for different TIA subpathways including those for V, C, and A and S [5, 22, 23, 38, 42, 46, 75]. C, A and S are synthesized in root, stem, leaves, and flowers [50, 74], while $\mathrm{V}, \mathrm{VB}$, and $\mathrm{VC}$ are synthesized only in leaves and flowers [74]. Many of the structural and regulatory genes, enzymes and intermediates that determine the pathway and various cell types of different organs in which specific steps of pathway are accomplished have been identified and characterized [15, 20, 50,67]. Processes involved in the biosynthesis of $\mathrm{V}, \mathrm{C}, \mathrm{VB}$, and $\mathrm{VC}$ in leaves are understood in some detail $[5,10,22,23,37,38,42,44,46$, $56,57,66,75]$. Strictosidine, is synthesized in epidermal cells, serves as a precursor for $\mathrm{V}$ and $\mathrm{C}$ synthesis in leaf $[2$, $18,23,29,48,49,57,66,76]$. C synthesized in the leaf epidermis via as yet unknown subpathway is excreted for deposition in its waxy layer [66]. Majority of the steps from cathenamine to $\mathrm{V}$ are known $[5,42,49,50,56,57,75,76]$. Early part of V subpathway from strictosidine is accomplished in epidermal cells $[29,57,66]$ while late steps and deposition of $\mathrm{V}$ occurs in the inner parenchymatous cells (laticifers and idioblasts; 8). $\mathrm{V}$ and $\mathrm{C}$ translocated to a common compartment in leaf cells are dimerized for the synthesis of VB and VC [66]. Ajmalicine (A) is synthesized from cathenamine via a reductive step $[15,26]$ and oxidation of $\mathrm{A}$ leads to synthesis and deposition of $\mathrm{S}$ in cellular vacuoles $[3,52]$. The TIA biosynthetic pathway at many stages of its progression involves translocation steps whereby intermediates are shuttled between cell types and intra-cellular compartments [4, 22, 50, 57, 66, 67, 76].

Until recently, a large body of work on $C$. roseus has remained focused on metabolic engineering to develop resources for $\mathrm{V}$ and $\mathrm{C}$ that may be more economic than their conventional resource, the roots and/or leaves produced on field grown $C$. roseus plants [78, 85, 87]. Metabolic engineering efforts to develop seeds, shoot, hairy root, cell suspension cultures, and heterologous organisms competent to hyper-synthesize V, C, and VB have been largely unsuccessful [17, 28, 52, 55, 63, 69, 82, 83].
Economic harvest of TIA high value products by metabolic engineering awaits understanding of TIA pathway in much greater details $[50,63,75]$. Emphasis is required on the application of genetics-based breeding procedures for improving the $\mathrm{V}, \mathrm{C}, \mathrm{VB}$, and $\mathrm{VC}$ contents and yield of the organs that accumulate them in $C$. roseus.

Application of the conventional breeding procedures requires selection of segregants or recombinants in populations derived from the designed hybrids, in which the desired alkaloid(s) are accumulated in abundance. The breeding work has been apparently constrained by the expensive and time consuming nature of the organ-wise alkaloid profiling procedures [27, 74]. In these circumstances, QTL identification and mapping is a powerful genetic approach to tag favorable genes/alleles of traits of interest with DNA markers [45]. Subsequently, it is possible to introgress desirable alleles associated with QTLs into medicinal germplasm by marker-assisted selection (MAS) breeding [45]. Availability of germplasm lines of $C$. roseus with high content of $\mathrm{C}, \mathrm{V}, \mathrm{VB}, \mathrm{S}$, and/or $\mathrm{A}$ will lower the cost of production of TIA drugs. Accumulation of an alkaloid in C. roseus organ may consist of three broad components: synthesis [15], deposition [41], and loss by catabolism [14]. Each of these is expected to be under polygenetic control and therefore alkaloid concentration in an organ of C. roseus is expected to be amenable for QTL analysis. Markers linked to QTLs can be scored at early stage of plant growth [74] and breeding lines containing low levels of alkaloids can be eliminated early in breeding if MAS is used. Besides, MAS would allow simultaneous selection of breeding lines for several traits [11, 45].

The objective of present study was to develop a segregating population of large size, to use it on the one hand to develop a frame work genetic map of DNA markers and on the other hand to characterize the variation in the mapping population by phenotypic analysis of the traits of interest, identify QTLs contributing to the variation in the traits and map the QTLs with reference to DNA markers. For the first time, 20 QTLs have been identified for 3 leaf traits in C. roseuspercent contents of $\mathrm{C}, \mathrm{V}$, and $\mathrm{VB}$ in leaves and 3 root traitspercent contents of $\mathrm{C}, \mathrm{A}$, and $\mathrm{S}$ in roots. Nine of the 10 QTLs identified for the contents of V, C, and VB in leaves and 4 out of 4 QTLs for $\mathrm{C}$ content in roots proved effective in the isolation a genotype from the mapping population leaves and roots of which were rich in the valuable alkaloids.

\section{Materials and Methods}

\section{Mapping Population}

The mapping population of 191 recombinant inbred lines (RILs) derived by single seed descent from a pair cross 
between the line called ' $l l i$ ' [36] and the floricultural cultivar 'Delhi Pink' [54] was used in the present study. The ' $l l i$ ' line is the renamed $g s r-8$ ethylmethanesulfonateinduced mutant in the glycophytic salinity response-8 $(G S R-8)$ gene in the background of white flower bearing and Pythium aphinadermatum tolerant medicinal cultivar 'WH40' or 'Nirmal' [1, 35, 61]. The cv 'Delhi Pink' bears pink color flower petals. In its compound, racemose inflorescence flowers are borne in pairs subtended by one of the two leaves per node. Moreover, the altered inflorescence of lli plants has axes that are much branched with leaves missing from the flowering nodes. Thus, LLI and lli inflorescence phenotypes serve as morphological marker. The parental lines have been shown to be genetically distant by morphological, biochemical, and molecular analysis $[54,70,74]$. The genomic DNA of 'lli' is hypomethylated as compared to that of 'Delhi Pink' (unpublished observation). Both the parents had been shown to synthesize and accumulate pharmaceutically important TIAs, 'Delhi Pink' plants at higher level than the ' $l l i$ ' plants. An $\mathrm{F}_{1}$ product of mating was self pollinated to produce $212 \mathrm{~F}_{2}$ progeny. Few RILs that produced sick or poorly fertile plants or continued to segregate (for $L L I$ and lli habit or flower color) were rejected. The $F_{2: 6}$ and $F_{2: 7}$ RIL populations were phenotyped in the year 2007 and 2008, respectively. Leaf samples for genotyping were taken from $\mathrm{F}_{2: 7}$ RILs grown separately.

\section{Field Trials}

Parents and all of 191 RILs were phenotyped for six traits; namely, percent vindoline concentration in leaves (VL), percent catharanthine concentration in leaves (CL) and roots (CR), percent vinblastine and vincristine concentrations in leaves (VBL), percent serpentine (SR) and ajmalicine (AR) in roots. Field trials for this purpose were conducted at the institute's (NIPGR) farm at New Delhi (latitude $28^{\circ} 36 \mathrm{~N}$; longitude $77^{\circ} 12 \mathrm{E}$; altitude $216 \mathrm{~m}$ ). The fields used in 2007 and 2008 trials were different and had been vacated by garden pea and wheat crops, respectively. Each trial was laid in randomized block design, replicated two times. There were 5 plants/genotype in a $1.5 \mathrm{~m}$ row and the distance between rows was $0.5 \mathrm{~m}$ ( $\sim 66$ thousand plants $\left.\mathrm{ha}^{-1}\right)$, in each replication. Each year seeds were sown in nursery in the middle of February in clay pots and transplanted in the field in mid-April. Three plants were harvested per genotype per replication in the middle of September. The period from seed sowing to harvest spanned spring, summer and monsoon seasons. The crop growth period in the year 2008 was relatively warmer and wetter. There were 220.6 thermal degree days (TDD) in 2008 as compared to 210.7 in 2007 during 15 April-15 September. The total rainfall from April to September in the years 2007 and 2008 was 49.7 and $84.9 \mathrm{~cm}$, respectively. The N, P, K, and S fertilizers were applied to the fields at the rate of $80,40,40$, and $10 \mathrm{~kg} \mathrm{ha}^{-1}$, respectively. The cultivation conditions standardized earlier were used [34, 54]. The plants identified for harvesting were scored for $l l i / L L I$ and petal color features, dug out, their roots washed free of adhering soil, placed in paper bags and kept for drying in a shed which was circulated with stream of air at room temperature. Leaves and roots from the three dry plants of a replication of a genotype were pooled and weighed. The replication-wise leaf and root materials of RILs, and parents were sampled for alkaloid extraction and quantification.

\section{Quantification of Alkaloids}

The alkaloids were extracted from leaf and root samples at room temperature and analyzed by RP-HPLC [73], with some modifications. Each sample was extracted and analyzed twice. For extraction of alkaloid content, finely powdered $1 \mathrm{~g}$ each of leaves and roots were left overnight in methanol $(3 \times 30 \mathrm{~mL})$, filtered, and concentrated under vacuum to dryness. The extract, defatted with hexane $(3 \times 10 \mathrm{~mL})$, was acidified by addition of $3 \% \mathrm{HCl}$ (15 mL). The acidified extract, made alkaline ( $\mathrm{pH} 8-9)$ by dropwise addition of liquor ammonia (about $25 \% \mathrm{NH}_{3}$ ), was further extracted with chloroform $(3 \times 30 \mathrm{~mL})$, washed with water, then dried over anhydrous sodium sulfate and finally concentrated in vacuo to give the alkaloid extract. The extracts were stored at $4{ }^{\circ} \mathrm{C}$ till further investigation. For LC analysis, each extract was redissolved in 1 and $5 \mathrm{~mL}$ HPLC grade methanol.

Chromatographic separation of the alkaloids was performed through a Shimadzu (Kyoto, Japan) LC-10ATvp gradient HPLC equipped with two LC-10ATvp pumps, controlled by a SCL-10A interface module, and SIL10ADvp autoinjector. For identification of peak(s) corresponding to the alkaloid(s) under investigation and checking its peak purity, a SPD-M 10Avp PDA detector (Shimadzu, Japan) was used. A Phenomenex (CA, USA) Luna C18 (2) $(250 \times 4.6 \mathrm{~mm} ; 5 \mu \mathrm{m})$ reversed-phase column was used for all the LC analysis. The mobile phase consisting of acetonitrile and $0.1 \mathrm{M}$ phosphate buffer $(\mathrm{pH}$ 4.9) was deployed as: linear gradient from $20: 80$ to $65: 35$ $(\mathrm{v} / \mathrm{v})$ in $0-30 \mathrm{~min}$ and $65: 35(\mathrm{v} / \mathrm{v})$ to $20: 80(\mathrm{v} / \mathrm{v})$ in 30-35 min (column rinsing); 35-40 min, isocratic elution with 20:80 (v/v) (column equilibration). A constant flow rate of $1.2 \mathrm{~mL} / \mathrm{min}$ was maintained during analysis and all injections were of $10 \mu \mathrm{L}$. The detection of peaks was carried out at a wavelength of $220 \mathrm{~nm}$. Identification and quantification of the alkaloids were achieved by comparison of their absorbance with that of the external standards. Standard stock solutions containing $1 \mathrm{mg} / \mathrm{mL}$ of VC, VB, 
A (Sigma Aldrich, USA), C (Alexix Corporation, Switzerland), V, and S (gifted by R. Verpoorte) were prepared in methanol and stored at $-20{ }^{\circ} \mathrm{C}$. These stock solutions were suitably diluted to prepare calibration plots for estimation of the percent content of the individual alkaloids in leaf and root extract.

\section{Statistical Analysis}

The software SPSS16.0 (SPSS, Chicago, USA) was used for the analysis of variance (ANOVA), application of $t$ test and estimation of correlation coefficients. Because the phenotypic trait values for genotypes for 2007 and 2008 were significantly correlated and trait-wise mean values of RILs for 2007 and 2008 did not differ significantly, the trait-wise ANOVA was performed on the combination of 2007 and 2008 data to estimate variation due to genotypes, year (season) and genotype $\times$ season interaction. The broad-sense heritability $\left(h^{2}\right)$ estimates were also derived from the combined data of 2007 and 2008 seasons.

\section{Framework Genetic Linkage Map Construction}

A framework genetic linkage map of the mapping population with 172 molecular markers and the lli/LLI morphological marker was already available [6]. The map of 8 linkage groups is based exclusively on the DNA markers that segregant-wise repeatedly gave the same result and segregated in Mendelian fashion among the 191 RILs of the mapping population. The map has markers elicited by 84 randomly amplified polymorphic DNA (RAPD) primers (called OP, followed by a capital letter identifying the primer set markers), 11 inter simple sequence repeat (ISSR) primers (called U markers), 39 simple sequence repeat (SSR) primer pairs (called CrSSR markers), 30 established sequence tag (EST)-SSR primer pairs (called CrES markers) and 8 microRNA primers (called CrMR markers). In addition, $37 \mathrm{CrES}$ primers were used to detect polymorphism using the PCR and electrophoresis conditions similar to those described by Chaudhary et al. [6]. Previously mapped markers together with the new markers were used to perform the linkage analysis in the mapping population using MAPMAKER 3.0 [40, 43]. Marker order and distances between markers were calculated using the Kosambi mapping function.

\section{QTL Analysis}

A framework map with an average marker density of $10.0 \mathrm{cM}$ was used for QTL dissection of quantitative traits. QTL analyses were implemented in QTL Cartographer Version 2.5 (http://statgen.ncsu.edu/qtlcart/WQTLCart.htm ) [81]. First, data were analyzed to identify markers associated with variation for each trait by use of single marker analysis (SMA) using all loci at a statistical threshold of $P<0.01$. Second, trait data were analyzed with simple interval mapping (SIM) [24, 39] and composite interval mapping (CIM) [86] to identify and confirm the presence of QTLs. The maximum LOD score of association between the genotype and trait data were calculated for SIM and CIM, and QTL predictions were accepted for SIM for values greater than a threshold value of 2.5 . The CIM analysis was run using Model 6 with forward and backward stepwise regression, a window size of $10 \mathrm{cM}$, and $2 \mathrm{cM}$ walking speed along chromosomes. The genome-wide LOD score thresholds $(P<0.05)$ for QTL detection were determined with 1,000 permutations $[8,13]$. The location of a QTL, LOD score, and percent phenotypic variance $\left(R^{2}\right)$ were estimated by CIM for each QTL. The QTL nomenclature was the following: $\mathrm{q}$ the abbreviation for quantitative trait, followed by abbreviation for trait name and by the number of QTL for that trait. For example, the QTL $q V L 1$ means QTL number 1 for the trait percent vindoline content in leaves and the QTL $q C R 2$ means QTL number 2 for percent catharanthine content in roots.

\section{Results}

Variation for Alkaloid Concentrations in the RIL Population

The mean values and ranges of the six alkaloid traits for the two parental lines and $191 \mathrm{~F}_{2: 6}$ and $\mathrm{F}_{2: 7}$ RILs based on the field trials conducted in 2007 and 2008 are shown in Table 1. The table also presents the means and ranges separately for the RILs bearing lli and LLI phenotypes. The results of analysis of variance on the RILs for the six traits are shown in Table 2. The frequency distributions of all the traits showed continuous variation (Fig. 1). Transgressive segregation was observed in both the directions. The analysis of variance indicated existence of highly significant variation among RILs for all the traits. These features of RILs showed that multiple genes were involved in the determination of the traits and the population of RILs was suitable for QTL mapping of the traits under examination.

The $\mathrm{C}, \mathrm{V}$, and VB concentrations in leaves and $\mathrm{S}$ and $\mathrm{C}$ concentrations in roots were similar in 2007 and 2008. The A content in roots differed between 2007 and 2008. The coefficients of correlation between RIL-wise observations recorded in 2007 and 2008 for all the alkaloid traits were positive and significant indicating general concord between the corresponding year-wise data. Between the parents VL, VBL, and CR were at higher levels in "Delhi Pink" than "lli", and AR is somewhat higher in "lli" than in "Delhi Pink." However, these differences were not statistically significant. Mean values of RIL population were intermediate of parental values for VL, 


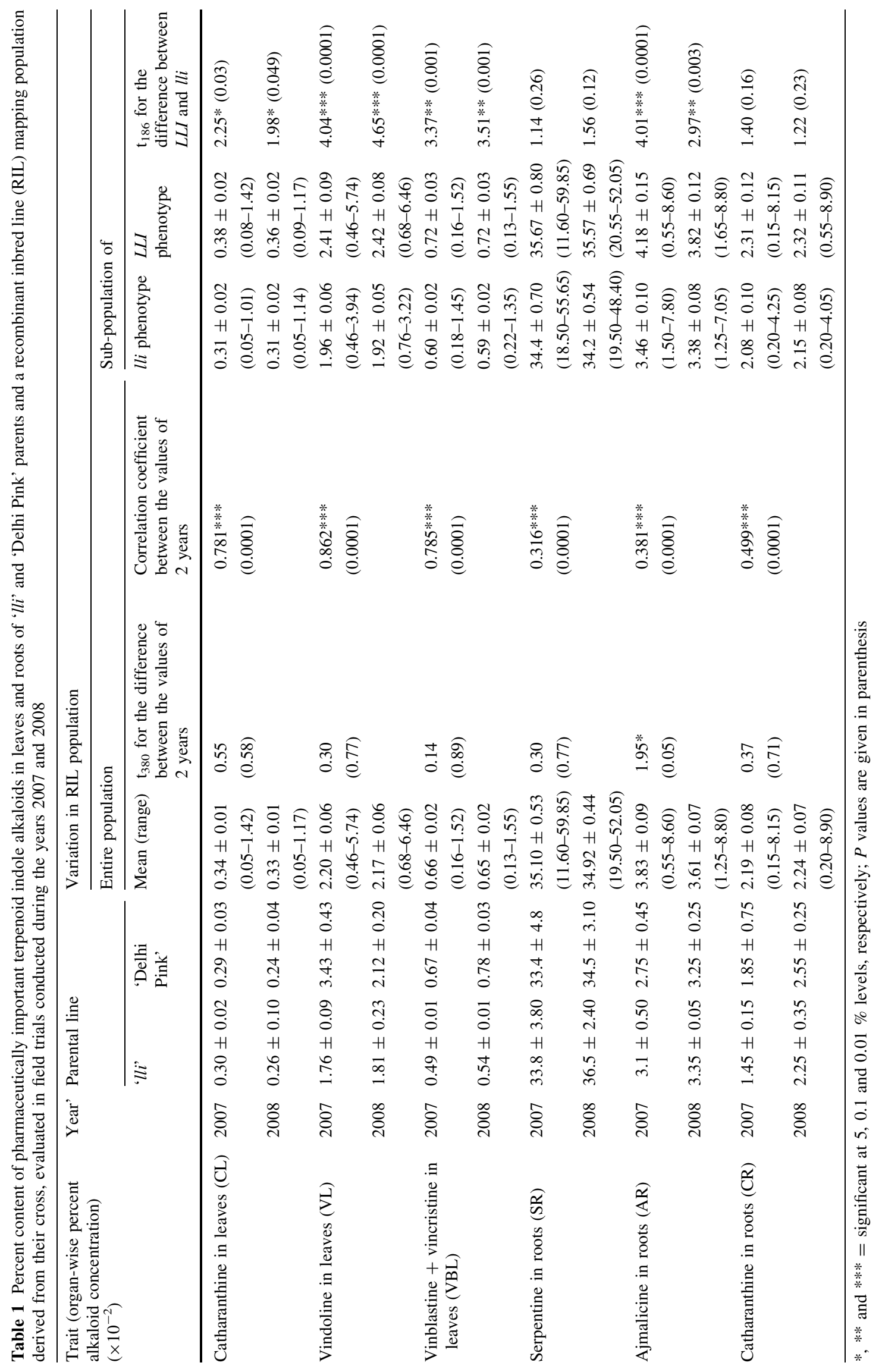


Table 2 Significance of variation due to genotypes, seasons and seasons $\times$ genotypes and estimates of broad-sense heritability for the alkaloid traits in the trial of $191 \mathrm{~F}_{2: 6}$ and $\mathrm{F}_{2: 7}$ recombinant inbred lines developed from the cross 'lli' $\times$ 'Delhi Pink' in Catharanthus roseus (f and $h^{2}$ values are provided)

\begin{tabular}{llcll}
\hline Trait $^{\mathrm{a}}$ & \multicolumn{2}{l}{ Analysis of variance components in RILs } & Heritability $h^{2}(\%)$ \\
\cline { 2 - 4 } & $\begin{array}{l}\text { Genotype } \\
\mathrm{f}_{190: 381}\end{array}$ & $\begin{array}{l}\text { Season } \\
\mathrm{f}_{1: 381}\end{array}$ & $\begin{array}{l}\text { Genotype } \times \text { season } \\
\mathrm{f}_{190: 381}\end{array}$ & 64.6 \\
\hline $\mathrm{CL}$ & $9.55^{*}$ & 1.63 & $1.21^{\mathrm{NS}}$ & 79.2 \\
$\mathrm{VL}$ & $9.92^{*}$ & 0.47 & $0.74^{\mathrm{NS}}$ & 41.3 \\
$\mathrm{VBL}$ & $9.90^{*}$ & 0.11 & $1.19^{\mathrm{NS}}$ & 50.1 \\
$\mathrm{SR}$ & $5.95^{*}$ & 0.40 & $3.13^{*}$ & 15.4 \\
$\mathrm{AR}$ & $7.12^{*}$ & $19.80^{*}$ & $3.26^{*}$ & 61.0 \\
$\mathrm{CR}$ & $11.5^{*}$ & 1.05 & $3.87^{*}$ & \\
\hline
\end{tabular}

$N S$ not significant $(P>0.05)$

* Significant at $P<0.0001$ probability level

${ }^{\text {a }}$ The description of the six traits is given in the Table 1

VBL, and CR and higher than parental values for CL and AR. Among the traits studied, VL was the most highly expressed (from 0.0046 to $0.0646 \%$ ). Leaf traits could be arranged in the following order in terms of their level of expression: $\mathrm{VL}>\mathrm{VBL}>\mathrm{CL}$. Among the root traits, SR expression was the highest (from 0.1161 to $0.5985 \%$ ). The root traits fell in the following order in terms of their relative expression: SR $>$ CR $>$ AR. On average basis the RILs of LLI phenotype had significantly higher contents of leaf and root alkaloids, except for S in roots; both lli and LLI RILs had similar SR expression. The RILs of LLI and lli phenotype separately and together demonstrated enormous variation in both the directions of mean values for all the six alkaloid traits studied.

Heritability of the Alkaloid Traits

The broad-sense estimates of the heritability of the six alkaloid traits are presented in Table 2 . The heritability $\left(h^{2}\right)$ values indicate the proportion of genetic variation in the expression of the total phenotypic variation in RILs for individual traits. The heritability ranged from $15.4 \%$ for AR to $79.2 \%$ for VL. The traits could be arranged in the following order in terms of their heritabilities: VL $(79.2 \%)>\mathrm{CL} \quad(64.6 \%)>\mathrm{CR}$ $(61.0 \%)>\operatorname{SR}(50.1 \%)>\operatorname{VBL}(40.3 \%)>\operatorname{AR}(15.4 \%)$. As is evident from the above data the heritability of AR was significantly lower than all the other studied alkaloids.

Correlations of the Alkaloid Concentrations in RIL Population

Correlation estimates are presented in the Table 3. Phenotypic correlation analysis revealed that correlations were positive and significant between the VL, CL, and VB $(+\mathrm{VC})$ leaf traits in all pair-wise combinations. The pair- wise correlations between $\mathrm{SR}, \mathrm{AR}$, and $\mathrm{CR}$ were also positive and significant. However, the correlations of the leaf traits VL and VBL with root traits (SR, AR, and CR) were weakly positive but insignificant. Contrastingly, the correlations of CL with root alkaloid traits were negative, but feeble and insignificant. The correlation analysis showed that accumulation of the studied alkaloids in leaves was independent of that in roots and vice versa.

\section{Advancement in the Framework Genetic Linkage Map}

The genetic linkage framework map of $C$. roseus constructed earlier by us had 172 DNA markers and 1 morphological marker [6]. By following the procedures briefly described here and in detail previously [6], $6 \mathrm{CrES}$ markers were added into the map of 8 linkage groups (LGs): CrES361, CrES392 and CrES401 into LG1, CrES364 into LG2, CrES377 into LG5 and CrES390 into LG8. Table S1 gives a list of all the CrES primer pairs that were tested and sequences of those which led to addition of markers on the map. Figure 2 shows the advanced version of the framework genetic linkage map (with QTLs placed on it). As a result of the advancement, the map has 84 RAPD, 11 ISSR, 39 SSR (anonymous) markers, 8 microRNA, 36 EST-SSR (coding region) markers and 1 morphological marker. The total map length now measures $1,786.5 \mathrm{cM}$, with an average distance of $10.0 \mathrm{cM}$ between markers. The longest linkage group has 45 markers covering a genetic distance of $320.1 \mathrm{cM}$. The shortest linkage group of $89.9 \mathrm{cM}$ genetic distance has 12 markers. The different types of markers on LGs are in proportion of the genetic distance between their markers. Three markers on LG3 have genetic distance $>25 \mathrm{cM}(26.2-28.1 \mathrm{cM})$. None of the markers are $\geq 30 \mathrm{cM}$ apart. All of 179 markers are uniquely located on the map. 

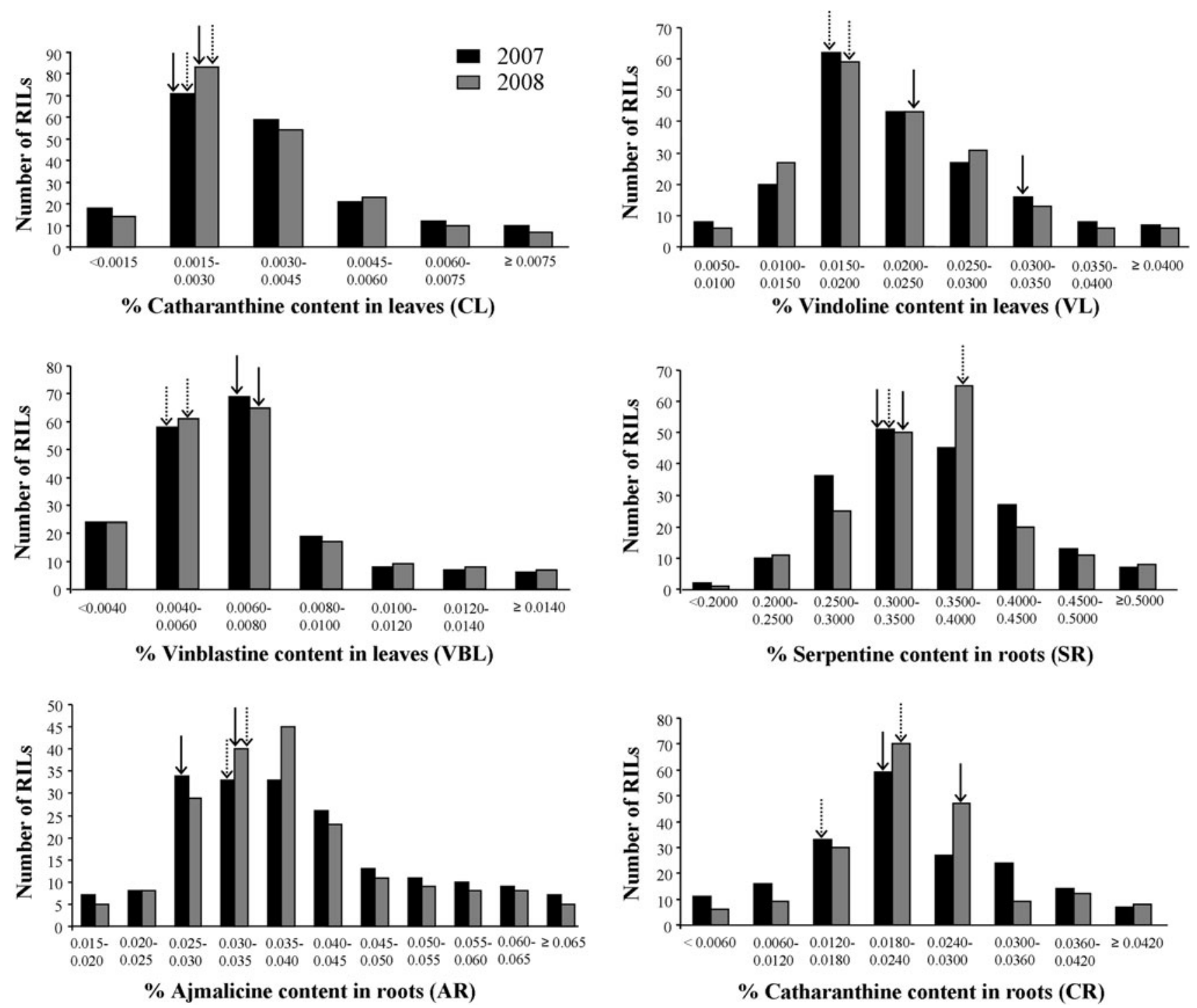

Fig. 1 Frequency distributions of the terpenoid indole alkaloid content traits measured during 2007 and 2008 in the 'lli' $\times$ 'Delhi Pink' $F_{2: 6}$ and $F_{2: 7}$ population(s). Arrows indicate the alkaloid levels

Table 3 Coefficients of correlation between the percent contents of vindoline (VL), catharanthine (CL), and vinblastine + vincristine (VBL) in leaves and catharanthine (CR), ajmalicine (AR) and serpentine (SR) in roots, among the recombinant inbred lines of the cross "lli" $\times$ "Delhi Pink" in Catharanthus roseus

\begin{tabular}{llllll}
\hline Trait & VL & CL & VBL & SR & AR \\
\hline CL & $0.487^{* *}$ & & & & \\
VBL & $0.387^{* *}$ & $0.417^{* *}$ & & & \\
SR & 0.090 & -0.025 & 0.034 & & \\
AR & 0.071 & -0.021 & 0.058 & $0.337^{* *}$ & \\
CR & 0.005 & -0.059 & 0.052 & $0.214^{*}$ & $0.569 * *$
\end{tabular}

* and ** significant at $P<0.01$ and $P<0.001$ probability level, respectively

in the parental lines. Dashed and solid arrows indicate the 'lli' parent and 'Delhi Pink' parent, respectively

Detection of Leaf and Root Alkaloid QTLs

Quantitative trait loci analysis was performed on all the six alkaloid traits in the RIL mapping population using the 179 markers distributed over 8 linkage groups (LGs) on the map. Application of all the three analytical methodsSMA, SIM and CIM-identified a total of 20 QTLs across the traits, 10 QTLs each for the leaf-and root—organ related alkaloid traits. Significant associations were detected between the six traits and markers located at various positions on the LGs 1, 3, 4, and 6 while markers on LGs 2, 5,7 , and 8 of the map were not found associated with any of the six traits (Table 4; Fig. 2). Of the total QTLs, 11 


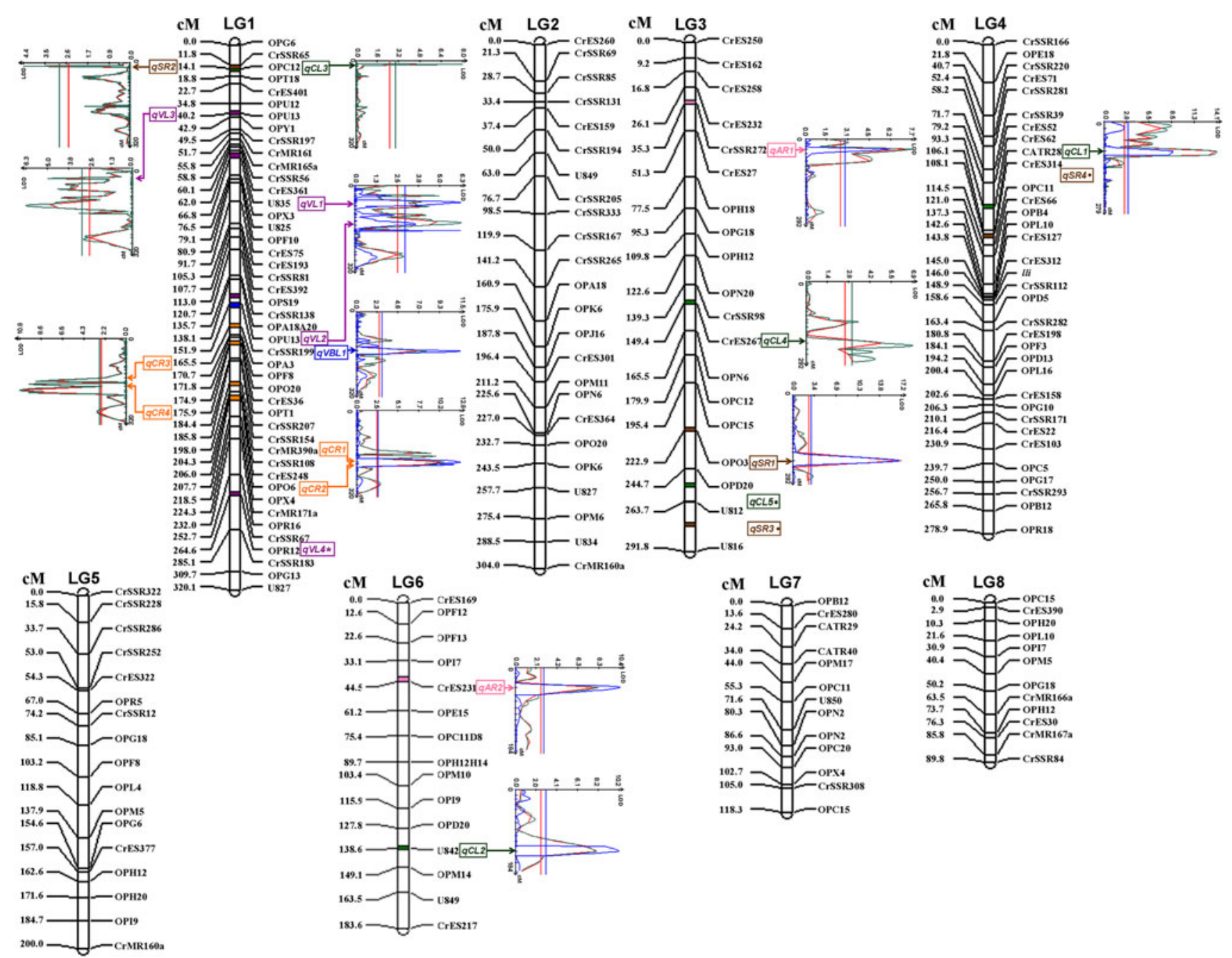

Fig. 2 Framework genetic linkage map of C. roseus showing 20 quantitative trait loci (QTLs) identified for the terpenoid indole alkaloid content traits using single marker analysis (SMA), simple interval mapping (SIM) and composite interval mapping (CIM) in the leaves and roots of 191 recombinant inbred lines of the cross "lli" $\times$ "Delhi Pink". The QTLs shown in map are for the traits: catharanthine (CL), vindoline (VL), vinblastine + vincristine (VBL) content in leaves and serpentine (SR), ajmalicine (AR), catharanthine (CR) content in roots. QTLs were designated using $q$ as abbreviation for QTL, followed by an abbreviation of the trait name in upper case

QTLs were found located on LG1, 5 QTLs on LG3 and 2 QTLs each on LG4 and LG6.

\section{Leaf Alkaloid Traits}

\section{$C L$}

A total of 5 QTLs were identified for CL. Of these, only two, $q C L 1$ on LG4 and $q C L 2$ on LG6, demonstrated significance with all the three analytical methods. The $q C L 3$ and $q C L 4$ detected on LG1 and LG3, respectively, were not significantly detected by CIM method. The qCL5 was not and a number identifying the QTL number for the trait. For each QTL, its name and the peak region on the concerned LG has been differentially indicated by a color: green for $\mathrm{CL}$, violet for $\mathrm{VL}$, blue for VBL, brown for SR, pink for AR and orange for CR. Graphical representations from QTL Cartographer using SMA (as red peak), SIM (as green peak) and CIM (as blue peak) for QTLs depicted by at least two methods are shown near the closest linked marker. The QTLs identified by either SMA or SIM only has been denoted by a asterisk and bullet, respectively. (Color figure online)

detected to be significant by SMA and CIM methods. Individually, the 5 QTLs accounted for the phenotypic variance in the range of $11.9-18.9 \%$.

\section{$V L$}

In all 4 QTLs were identified for VL. Among them $q V L 1$ and $q V L 2$ were identified by all of SMA, SIM, and CIM methods. The $q V L 3$ was identified by SMA and SIM methods while $q V L 4$ was identified only by SMA method. The VL QTLs were responsible for up to only $12.6 \%$ phenotypic variance. All the four VL QTLs were located on LG1. 


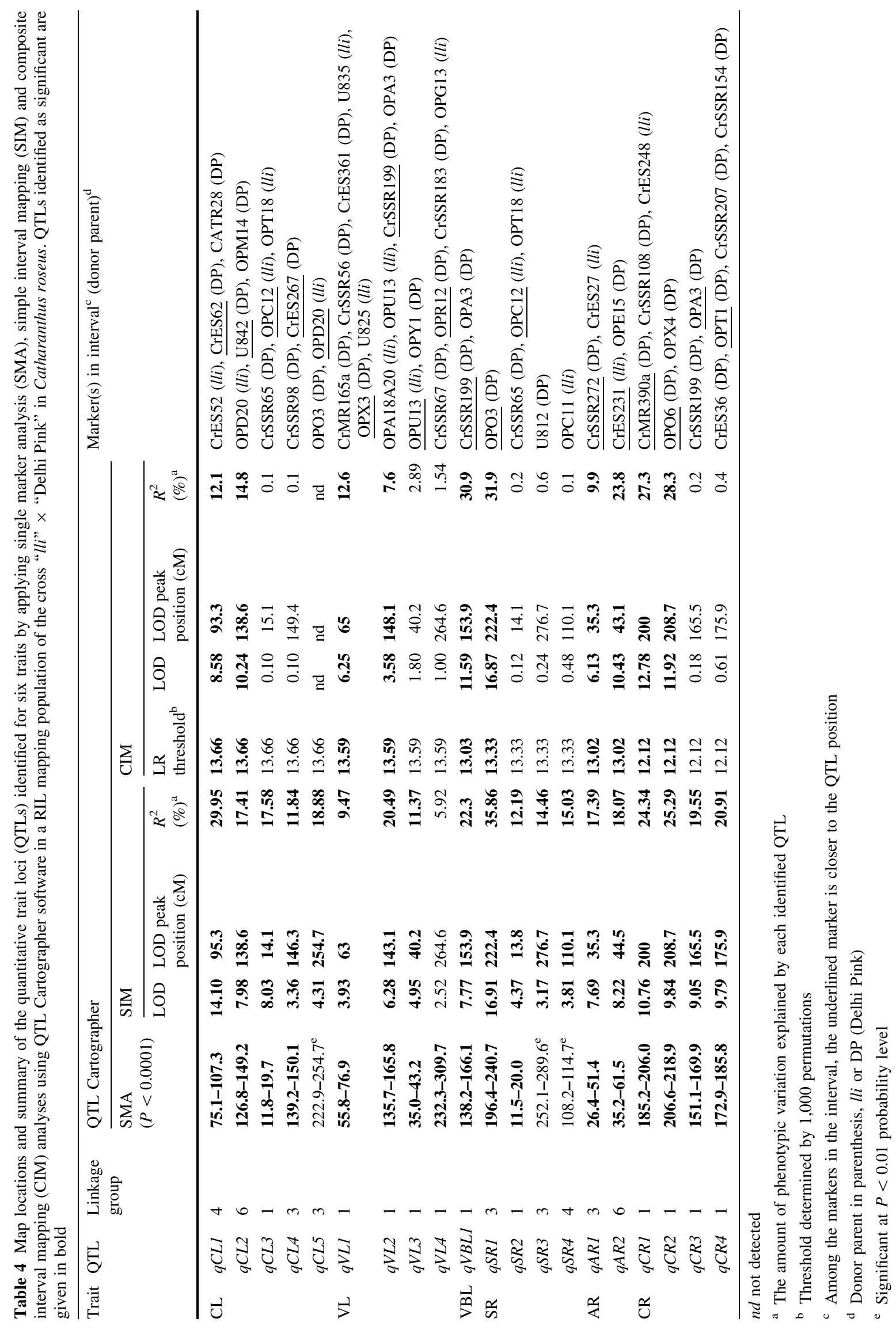


$V B L$

Only one QTL $q V B L 1$ located on LG1, was detected for the VBL trait. This $q V B L 1$ must be a major QTL since it explained $40 \%$ of the phenotypic variance detected in the expression of VBL.

\section{Root Alkaloid Traits}

\section{$C R$}

A total of 4 QTLs were detected, $q C R 1$ and $q C R 2$ by the SMA, SIM, and CIM methods; and $q C R 3$ and $q C R 4$ by SMA and SIM methods only. All the qCRs were mapped on LG1. They individually explained $19.6-28.3 \%$ of the observed phenotypic variance in this trait.

\section{$A R$}

Two qARs, one each on LG3 and LG6 were detected by all the three analytical methods. The $q A R 1$ and $q A R 2$ were respectively responsible for 9.9 and $23.8 \%$ of the phenotypic variance in the trait.

\section{$S R$}

Four QTLs were identified for this trait, $q S R 1$ on LG3 by all the three detection methods, $q S R 2$ on LG1 by SMA and SIM methods and $q S R 3$ on LG3 and $q S R 4$ on LG4 by the SIM method. These 4 QTLs explained 12.2-31.9\% of the observed phenotypic variance for SR.

\section{Co-Localization of QTLs on Linkage Groups}

The QTLs for the same and/or different traits were observed to be co-located on the linkage groups (Fig. 2). On LG1, of the 11 QTLs, 10 fell into three regions. All the QTLs related to CR fell in a $65.9 \mathrm{cM}$ region on LG1 from 152.1 to $218.9 \mathrm{cM}$. An interval of $30.4 \mathrm{cM}$ from 135.7 to $166.1 \mathrm{cM}$ included two QTLs, $q V L 2$ and $q V B L 1$, both for leaf alkaloids. There was an overlap of $27.6 \mathrm{cM}$ between the $q V L 2(135.7-165.8 \mathrm{cM})$ and $q V B L 1(138.2-166.1 \mathrm{cM})$. Another region of $65.4 \mathrm{cM}$ spanning $11.5-76.9 \mathrm{cM}$ distance on the upper part of LG1 contained four QTLs, namely $q S R 2$ (peaking at $14.1 \mathrm{cM}$ location), $q C L 3$ $(15.1 \mathrm{cM}), q V L 3(40.2 \mathrm{cM})$ and $q V L 1(65 \mathrm{cM})$, three QTLs for leaf traits and a QTL for root trait. On LG3, a $93.2 \mathrm{cM}$ region from 196.4 to $289.6 \mathrm{cM}$, included $q S R I$ (peak at $222.4 \mathrm{cM}), q C L 5(254.7 \mathrm{cM})$ and $q S R 3(276.7 \mathrm{cM})$, QTLs for leaf and root traits. Another coincidental location of leaf and root QTLs was $q C L 1(93.3 \mathrm{cM})$ and $q S R 4$
$(110.1 \mathrm{cM})$ in a $39.6 \mathrm{cM}$ region from 75.1 to $114.7 \mathrm{cM}$ on LG4.

Relative Contribution of Favorable QTL Alleles for Leaf and Root Traits by Parents

Table 4 lists the markers that fall in the interval that defines the location of each of the 20 QTLs. The donor of each marker is also specified. It is seen that of the 45 markers that are listed against the 20 QTLs, 30 were from the Delhi Pink parent and 15 from the lli parent. Delhi Pink contributed more favorable alleles as compared to the lli. If the marker closest to the QTL was treated as index of donor, it appeared that $l l i$ and Delhi Pink, respectively, contributed 6 and 14 favorable QTL alleles.

\section{Discussion}

Medicinal cultivars rich in the pharmaceutically important terpenoid indole alkaloids (TIAs) are required in C. roseus. To enable the marker-assisted improvement of TIAs in $C$. roseus, 20 QTLs that affect the content of 5 important TIAs in roots and/or leaves have been identified. This is perhaps the first study of identification, mapping and validation of QTLs using combination of SMR, SIM and CIM analytical procedures in $C$. roseus. Some aspects of the analyses are discussed below.

Comparative Properties of the Alkaloid Traits in the Mapping Population

The contents of a specific TIA in different organs of C. roseus represent the organ-wise net accumulation of the TIA, outcome of the amount synthesized and saved from possible catabolism. The progress in the molecular genetic dissection of the TIA pathway in $C$. roseus has shown that the processes involved are under multigenic control [15, 20, 79]. The content of a TIA in an organ is therefore expected to be high in genotypes in which combination of alleles of the concerned genes favor increased synthesis and storage of the alkaloid in the organ. Genotypes harboring combinations of favorable alleles for improved expression of a trait (such as the content of TIA in an organ) are expected to occur in segregating populations from crosses between genetically variant germplasm. The mapping population of RILs characterized in this study, developed from the cross between "lli" (an inflorescence mutant of the medicinal cultivar "Nirmal") and "Delhi Pink" (a floricultural cultivar), indeed represents such a population. The RIL population demonstrated considerable variation in all the traits studied: VL, CL, VBL, CR, SR, and AR. Transgressive segregation was observed in the RIL population for all the traits. There were 
RILs in which the SR, VL, VBL, AR, CR, and CL traits were expressed at 1.6, 2.2, 2.4, 2.8, 4.0, and 4.6-fold higher level, respectively, as compared to the corresponding mean value of the parents. For each trait, a large component of the observed variation was of genetic nature, even though the parents of the mapping population did not differ significantly in the expression of all the six traits. The heritability estimates for all the traits except AR, were moderate to high in range. Interestingly, the ranges of variation were wide, and heritabilities for CL, CR, and VL traits were higher than for other traits. This result may be of much economic importance. VB and other more effective anticancer molecules are commercially semi synthesized from $\mathrm{V}$ and $\mathrm{C}$ which are also the natural precursors of VB [15, 58, 64]. The commercial processes uses $\mathrm{V}$ and $\mathrm{C}$ extracted from the leaves of the cultivated plants of $C$. roseus medicinal varieties. The detection of highly heritable genetic variation in the CL and VL traits in the RIL population indicates that the segregating populations from the cross "lli" $\times$ "Delhi Pink" offer possibilities for selection of genotypes bearing $\mathrm{V}$ and $\mathrm{C}$ rich leaves. The properties of CR trait in the RIL population also suggest possibilities of selection of genotypes bearing roots highly rich in $\mathrm{C}$. The $C$. roseus leaves contain several times $(8 \times)$ more $\mathrm{V}$ than $\mathrm{C}$. The commercial extracts of leaves therefore have relatively more $\mathrm{V}$ than $\mathrm{C}$, although semisynthesis of $\mathrm{VBL}$ requires $\mathrm{V}$ and $\mathrm{C}$ in equimolar concentrations. The imbalance between the quantities of $\mathrm{C}$ and $\mathrm{V}$ from leaves may be narrowed/overcome by extraction of $\mathrm{C}$ and $\mathrm{V}$ from whole plants of genotypes that bear hyper-C-rich roots, such as those available among the "lli" $\times$ "Delhi Pink" segregants. The studied RIL population indeed harbors individual RILs in which VL, CL, VBL, and CR are simultaneously very high (D54, VL 3.14, CL 1.32, VBL 0.95 and CR $\left.5.10 \times 10^{-2} \%\right)$.

In the RIL mapping population, the leaf traits CL, VL, and VBL were highly correlated with each other. Like wise the root traits were pair-wise correlated. Interestingly, the leaf traits did not correlate with the root traits. These results confirm similar conclusions arrived in an earlier study [74]. All these results have important implications. The absence of correlations between leaf and root traits means that the synthesis and storage of the $\mathrm{C}, \mathrm{V}$, and VB TIAs in leaf is autonomous of the corresponding processes for $\mathrm{C}, \mathrm{A}$, and $\mathrm{S}$ in roots. This inference is in conformity with the previous study of the expression of specific genes and/or enzymes involved in the synthesis of $\mathrm{V}$ in various tissues of leaves and roots borne on $C$. roseus plants and in in vitro cultures of hairy roots of $C$. roseus [15, 16, 20, 23, 50, 60, 78]. There is evidence that 16-methoxytabersonine, a precursor of vindoline synthesized in leaf epidermal cells is secreted into the cells of inner mesophyll tissue where $\mathrm{V}$ is synthesized and stored [20, 22, 23, 66]. $\mathrm{V}$ is not synthesized in normal roots and hairy roots $[20,63,74]$. $\mathrm{C}$ in leaves is synthesized in epidermal cells and accumulates in the wax associated with the surface of epidermis [66]. The assembly of $\mathrm{VB}$ from the $\mathrm{C}$ and $\mathrm{V}$ components probably occurs in the leaf epidermis $[10,66]$. The mechanism that shuttles $\mathrm{V}$ and $\mathrm{C}$ back into epidermal cells to enable VBL synthesis is presently obscure. VB is not synthesized in roots as $\mathrm{V}$ is not available there [78]. There is no evidence of any connection/transport of TIAs between root and leaf. The contents of $\mathrm{V}$ and $\mathrm{C}$ in leaves are expected to be correlated with each other because they are synthesized from a common precursor, the strictosidine [20-22, 66, 79]. The CL and VL are correlated with VBL because VBL is assembled from dimerization of $\mathrm{V}$ and $\mathrm{C}[15,66]$. Since the correlations between $\mathrm{V}$ and $\mathrm{C}, \mathrm{V}$ and $\mathrm{VB}$ and $\mathrm{C}$ and $\mathrm{VB}$ are high, it may be possible to produce genotypes, leaves of which are rich in all the three pharmaceutical TIAs.

$\mathrm{C}, \mathrm{A}$, and $\mathrm{S}$ are known to be synthesized in root tips [15, 20, 50, 63, 72, 74, 78]. A and S share a subpathway such that $\mathrm{S}$ is the product of $\mathrm{A}$ [15]. The common precursor for $\mathrm{C}$ and $\mathrm{A}$ is cathenamine $[16,20,21,50,66,79] . \mathrm{A}$ is derived from cathenamine in one step [20] while $\mathrm{C}$ is synthesized from cathenamine perhaps in multiple steps which remain to be understood. The AR and SR are expected to be correlated since they comprise a subpathway of TIA synthesis [15]. The CR and AR/SR are correlated because their precursor is common [15, 20, 79]. Among $\mathrm{C}, \mathrm{S}$, and $\mathrm{A}$, the $\mathrm{C}$ and $\mathrm{S}$ are end products and $\mathrm{A}$ is the intermediate for $S$. This may be the reason for high heritabilities for $\mathrm{CR}$ and $\mathrm{SR}$ as compared to $\mathrm{AR}$. It is possible to visualize that selection for $\mathrm{CR}$ or SR may result in co-selection for CR, AR and SR traits.

The existence of strong correlations among leaf traits on the one hand and root traits on the other hand raises the possibility that screening for a selected one or two traits might result in improvement of the organ-wise correlated traits. The autonomy in the expression of TIA pathway for $\mathrm{C}$ in roots and leaves is confirmed. Possibility of selection of genotypes simultaneously improved in VL, CL and CR is indicated.

\section{Suitability of Framework Genetic Linkage Map for QTL Analysis}

This study has used a 179 point genetic linkage map consisting of dominant and co-dominant markers. The map is based exclusively on the markers that segregated repeatedly according to Mendelian expectations among $191 \mathrm{~F}_{2: 7}$ RILs. The markers were placed on 8 LGs based on stringent mapping conditions. The total map length is $1,786.5 \mathrm{cM}$. The map distances on individual LGs range from 89.9 to $320.1 \mathrm{cM}$. The average inter-marker distance is $10 \mathrm{cM}$. The map has suitable number of evenly distributed markers on each LG. Although relatively unsaturated, 
the framework map is quite robust and thus suitable for QTL analysis [11]. It has 17 of the 92 markers mapped on a framework map using a different mapping population [71].

Detection and Validation of QTLs for Alkaloid Accumulation Traits

Detection of QTLs affecting the percent contents of pharmaceutically important TIAs in leaves and roots in this study has augmented the already available information on the genetic architecture of TIA accumulation in $C$. roseus organs. A total of 20 QTLs were identified. Considering the complexity of the processes involved in TIA accumulation (TIA synthesis, deposition and transformation/consumption by catabolism) the number of QTLs identified appears to be small. It is possible that QTLs affecting the most decisive steps of TIA accumulation for which the parents of RILs varied genetically got identified. Among the 20 QTLs identified, 5 were for CL, 4 each for VL, CR and SR, 1 for VBL and 2 for AR. The detection of QTLs may have been in proportion of the total QTLs affecting each of the trait. This idea is corroborated by existing information that many more steps are involved in the synthesis of V from the TIA central intermediate strictosidine and its deposition in leaf idioblast and laticifers (several genes for synthesis of tabersonine from strictosidine, six genes from tabersonine to $\mathrm{V}$, several genes for inter- and intra-cellular transport of intermediates and possibly a few genes each for stable deposition and regulation of the processes) $[4,5,20,22,57$, $60,66]$ than those involved for synthesis of VB from $\mathrm{V}$ and $\mathrm{C}$ and its accumulation (several steps including the dimerization reaction leading to $\alpha-3^{\prime}, 4^{\prime}$-anhydrovinblastine, a few genes for the transport of $\mathrm{C}$ and $\mathrm{V}$ to the site of VB synthesis and possibly a few genes for the stable deposition of VB and regulation of the processes) [10, 16, $22,23,60,66]$. Since A is an intermediate for $\mathrm{S}$, detection of 4 QTLs for SR and 2 QTLs for AR is also in agreement with the suggestion that the number of QTLs detected for a trait indicates the degree of complexity in its genetic determination. Presently, there is little information about the genetic architecture of subpathway that is responsible for synthesis of $\mathrm{C}$ from strictosidine, the intermediate shared with $\mathrm{S}$ subpathway in roots and $\mathrm{V}$ pathway in leaves. The detection of 5 QTLs for CL and 4 QTLs for CR traits indicates existence of multiple steps in the determination of $C L$ and $C R$, perhaps of the same magnitude as for the VL trait. To reveal new and larger arrays of QTLs for the presently studied traits, segregating populations from crosses between parents having more divergent expression of traits, and construction of more detailed genetic linkage map by integration of additional DNA markers, especially SSR and SNP markers, may be examined in future studies.
Linkage relationships of QTLs with each other and with co-located markers are multifariously informative. The QTLs for all the six traits studied here were mapped on 4 out of a total of $8 \mathrm{LGs}$ in the genome of $C$. roseus $(2 n=2 x=16)$. QTLs for 5 of the 6 traits, except for AR were mapped on LG1. All the QTLs for three traits VBL, VL, and CR were mapped on LG1. For the CL, AR, and SR, the QTLs were mapped on two or more of LGs. Co-localization of two QTLs of different traits may be indicative of involvement of common function in the determination of the traits. In the present study, there are two such examples. The QTLs $q C L 3$ and $q S R 2$ were found linked to the same marker OPC12 on LG1. This indicates that a gene located at the site of OPC12 perhaps determines both CL and SR traits. It could be any of the genes among those that determine TIA synthesis steps up to cathenamine, a post-strictosidine intermediate both for $\mathrm{C}$ in leaves and $\mathrm{S}$ in roots of $C$. roseus. Another set of two QTLs for distinct traits, namely $q V B L 1$ and $q V L 2$ were found linked to the same marker CrSSR199 in an interval of $30.4 \mathrm{cM}$ on LG1. Among all the QTLs, $q V B L 1$ accounted for the highest $(>30 \%)$ phenotypic variability demonstrated in its trait. The $q V B L 1$ and $q V L 2$ perhaps represent gene(s) concerned with the transport of $\mathrm{V}$ from its site of accumulation in leaf laticifers and idioblasts to the site of VB synthesis, most likely leaf epidermis. Interestingly, all the 4 QTLs for CR trait formed a cluster in a region of $66.8 \mathrm{cM}$ distance on LG1. This might suggest that the genes located at the sites of CR QTLs share regulatory mechanism(s). Contrastingly, the 5 QTLs for the CL traits were observed to be located on 4 different LGs. The $q C L 3$ was located far removed from the QTL cluster of CR trait on LG1. These observations imply that although CL and $\mathrm{CR}$ traits are concerned with accumulation of $\mathrm{C}$, albeit in different organs, their QTLs defined here apparently do not concern common gene functions. This finding supports the conclusion that $\mathrm{C}$ synthesis-cum-accumulation pathway involves many steps. Another interesting observation was that even though all of the QTLs for VL and CR were located on LG1, yet the VL and CR traits were not correlated. Since recombination frequency/chromosome/generation is usually low, an implication of co-occurrence of QTLs for different alkaloid accumulation traits on same LG is high level of co-inheritance of the QTLs/concerned traits. Location of QTLs for all the traits on 4 LGs of $1,074.4 \mathrm{cM}$ genetic distance, with the total exclusion of 4 LGs of $712 \mathrm{cM}$ genetic distance, indicates that perhaps $C$. roseus acquired TIA biosynthetic ability as a consequence of inter-species hybridization followed by selection of a $\mathrm{TIA}^{+}(n=8)$ diploid fertile derivative.

The mapping population of RILs demonstrated transgressive segregation for all the studied traits, even though the parents did not differ much in the phenotypic 
expression of the traits. Therefore, both the parents were expected to contribute favorable alleles for the expression of different traits. The observations confirmed that both the parents contributed favorable QTLs. However, it was found that "Delhi Pink" contributed more favorable alleles of QTLs than "Ili." All the favorable QTLs for the CR trait and the only one for VBL were contributed by Delhi Pink. The floricultural cultivar Delhi Pink was identified as resource of alleles for increased accumulation of pharmaceutically important alkaloids in $C$. roseus.

Feasibility of Marker-Assisted Breeding for Improvement of Alkaloid Contents

The characteristics of variation for 3 leaf and 3 roots TIA content traits in the mapping population indicate that the segregating populations of the "lli" $\times$ "Delhi Pink" cross may prove suitable for selecting superior genotypes for all the 6 traits. The TIAs V, C, VB, A, and S are materials for the production of drugs for three different kinds of clinical conditions. Unlike $\mathrm{A}$ and $\mathrm{S}$, for which there are alternate resources, C. roseus roots and/or leaves are the only resource for C, V and VB. Phenotyping of the 191 RILs had revealed a line designated D54 which had V, VB, and C in high concentrations in leaves and $\mathrm{C}$ in high concentrations in roots. Genotyping showed that D54 was positive for 13 out of 14 QTL alleles detected as favorable for CL (4/5), VL (4/4), VBL (1/1) and CR (4/4) traits. D54 possessed 9 out of 14 DNA markers identified closest to $q C L 2-q C L 4, q V L 2-q V L 4, q V B L 1, q C R 2$, and $q C R 4$ and 4 markers identified close to $q V L 1, q C R I$, and $q C R 3$; it did not possess the markers identified close to $q C L 1$. D54 exemplified the possibilities of exercising marker-assisted selection (MAS) for genotypes having improved VL, CL, and CR traits. A strategy combining MAS and phenotypic selection seems most appropriate at the current level of QTL analysis and relatively low density of markers on the genetic linkage map underlying the QTL analysis. It is suggested that the segregating populations of "lli" $\times$ "Delhi Pink" cross at young stages of growth in early generation(s) may be first subjected to genotyping in respect of markers close to the VL, $\mathrm{CL}$, and C QTLs. The smaller populations enriched via selection for favorable QTLs based on markers may then be phenotyped for the VL, CL, and CR traits to finally select genotypes simultaneously improved for the VL, CL, and CR traits.

\section{Summarized conclusion}

In C. roseus, a total of 20 QTLs for 3 leaf and 3 root TIA traits related to the economics of the production of important TIA drugs were identified. The QTLs were detected by combined use of the SMA, SIM, and CIM analytical procedures on a transgressively segregating population that also served as the genetic linkage mapping population for placement of 179 markers on the $8 \mathrm{LGs}$ of the $C$. roseus genome. The QTLs were mapped only on 4 of the 8 LGs, 2 each on two LGs and 5 and 11 on the other two LGs. Clusters of QTLs affecting the same or different traits were also detected. A two-step selection scheme combining the use of markers linked to QTL followed by phenotypic selection has been proposed for isolation of genotypes simultaneously improved for VL, CL, VBL, and $\mathrm{CR}$ traits from the segregating population(s) of the cross that gave the mapping population.

Acknowledgments Grateful thanks are due to the Director, NIPGR for allowing the use of facilities, Council of Scientific and Industrial Research (CSIR) and Indian National Science Academy for the award of scientistship schemes to SK, CSIR, and SKA Institute of Research, Education and Development for award of postgraduate fellowships to SC and VS, respectively, and to Swarup Parida for useful suggestions and him and Bithika Sharma for reading the manuscript. Help of Vinod Kumar in field work is also thankfully acknowledged.

\section{References}

1. Anonymous (1987) A superior variety of periwinkle resistant to die-bach disease developed. CIMAP Newslett 14:13

2. Barleben L, Panjikar S, Ruppert M, Koepke J, Stöckigt J (2007) Molecular architecture of strictosidine glucosidase: the gateway to the biosynthesis of the monoterpenoid indole alkaloid family. Plant Cell 19:2886-2897

3. Blom TJM, Sierra M, van Vliet TB, Franke-van Dijk MEI, de Koning P, van Iren F, Verpoorte R, Libbenga KR (1991) Uptake and accumulation of ajmalicine into isolated vacuoles of cultured cells of Catharanthus roseus (L.) G. Don. and its conversion into serpentine. Planta 183:170-177

4. Burlat V, Oudin A, Courtois M, Rideau M, St-Pierre B (2004) Co-expression of three MEP pathway genes and geraniol 10-hydroxylase in internal phloem parenchyma of Catharanthus roseus implicates multicellular translocation of intermediates during the biosynthesis of monoterpene indole alkaloids and isoprenoid-derived primary metabolites. Plant J 38:131-141

5. Campos-Tamayo F, Hernández-Domínguez E, Vázquez-Flota $F$ (2008) Vindoline formation in shoot cultures of Catharanthus roseus is synchronously activated with morphogenesis through the last biosynthetic step. Ann Bot 102:409-415

6. Chaudhary S, Sharma V, Prasad M, Bhatia S, Tripathi BN, Yadav G, Kumar S (2011) Characterization and genetic linkage mapping of the horticulturally important mutation leafless inflorescence (lli) in periwinkle Catharanthus roseus. Sci Hortic 129:142-153

7. Chockalingam S, Sundari MSN, Thenmozhi S (1989) Impact of the extract of Catharanthus roseus on feeding and enzymatic digestive activities of Spodoptera litura. J Environ Biol 10:303-307

8. Churchill GA, Doerge RW (1994) Empirical threshold values for quantitative trait mapping. Genetics 138:963-971

9. Collu G, Unver N, Peltenburg-Looman AM, van der Heijden R, Verpoorte R, Memelink J (2001) Geraniol 10-hydroxylase, a cytochrome P450 enzyme involved in terpenoid indole alkaloid biosynthesis. FEBS Lett 508:215-220

10. Costa MMR, Hilliou F, Duarte P, Pereira LG, Almeida I, Leech M, Memelink J, Barceló AR, Sottomayor M (2008) Molecular cloning and characterization of a vacuolar class III peroxidase 
involved in the metabolism of anticancer alkaloids in Catharanthus roseus. Plant Physiol 146:403-417

11. Dekkers JCM, Hospital F (2002) The use of molecular genetics in the improvement of agricultural populations. Nat Rev Genet 3:22-32

12. DeLuca V, Marineau C, Brisson N (1989) Molecular cloning and analysis of a cDNA encoding a plant tryptophan decarboxylase. Proc Natl Acad Sci USA 86:2582-2586

13. Deorge RW, Churchill GA (1996) Permutation test for multiple loci affecting a quantitative character. Genetics 142:285-294

14. El-Sayed M, Verpoorte R (2005) Methyljasmonate accelerates catabolism of monoterpenoid indole alkaloids in Catharanthus roseus during leaf processing. Fitoterapia 76:83-90

15. El-Sayed M, Verpoorte R (2007) Catharanthus terpenoid indole alkaloids: biosynthesis and regulation. Phytochem Rev 6:277-305

16. Facchini PJ, DeLuca V (2008) Opium poppy and Madagascar periwinkle: model non-model systems to investigate alkaloid biosynthesis in plants. Plant J 54:763-784

17. Geerlings A, Hallard D, Martı'nez-Caballero A, Lopes-Cardoso I, van der Heijden R, Verpoorte R (1999) Alkaloid production by a Cinchona officinalis 'Ledgeriana' hairy root culture containing constitutive expression constructs for tryptophan decarboxylase and strictosidine synthase cDNAs from Catharanthus roseus. Plant Cell Rep 19:191-196

18. Geerlings A, Ibanez MM, Memelink J, van der Heijden R, Verpoorte R (2000) Molecular cloning and analysis of strictosidine b-D-glucosidase, an enzyme in terpenoid indole alkaloid biosynthesis in Catharanthus roseus. J Biol Chem 275:3051-3056

19. Guirimand G, Burlat V, Oudin A, Lanoue A, St-Pierre B, Courdavault V (2009) Optimization of the transient transformation of Catharanthus roseus cells by particle bombardment and its application to the subcellular localization of hydroxymethylbutenyl 4-diphosphate synthase and geraniol 10-hydroxylase. Plant Cell Rep 28:1215-1234

20. Guirimand G, Courdavault V, St-Pierre B, Burlat V (2010) Biosynthesis and regulation of alkaloids. In: Pua E-C, Dowey MR (eds) Plant developmental biology-biotechnological perspectives, vol 2. Springer, Berlin

21. Guirimand G, Courdavault V, Lanoue A, Mahroug S, Guihur A, Blanc N, Giglioli-Guivarc'h N, St-Pierre B, Burlat V (2010) Strictosidine activation in Apocynaceae: towards a "nuclear time bomb"? BMC Plant Biol 10:182-201

22. Guirimand G, Guihur A, Ginis O, Poutrain P, Héricourt F, Oudin A, Lanoue A, St-Pierre B, Burlat V, Courdavault V (2011) The subcellular organization of strictosidine biosynthesis in Catharanthus roseus epidermis highlights several trans-tonoplast translocations of intermediate metabolites. FEBS J 278:749-763

23. Guirimand G, Guihur A, Poutrain P, Héricourt F, Mahroug S, St-Pierre B, Burlat V, Courdavault V (2011) Spatial organization of the vindoline biosynthetic pathway in Catharanthus roseus. J Plant Physiol 168:549-557

24. Haley CS, Knott SA (1992) A simple regression method for mapping quantitative trait loci in line crosses using flanking markers. Heredity 69:315-324

25. Hedhili S, Courdavault V, Giglioli-Guivarc'h N, Gantet P (2007) Regulation of the terpene moiety biosynthesis of Catharanthus roseus terpene indole alkaloids. Phytochem Rev 6:341-351

26. Hemscheidt T, Zenk MH (1985) Partial purification and characterization of a NADPH dependent tetrahydroalstonine synthase from Catharanthus roseus cell suspension cultures. Plant Cell Rep 4:216-219

27. Hisinger S, Jolicoeur M (2007) Analysis of Catharanthus roseus alkaloids by HPLC. Phytochem Rev 6:207-234

28. Hong SB, Peeble CAM, Shanks JV, San KY, Gibson SI (2006) Expression of the Arabidopsis feedback-insensitive anthranilate synthase holoenzyme and tryptophan decarboxylase genes in Catharanthus roseus hairy roots. J Biotechnol 122:28-38
29. Irmler S, Schröder G, St-Pierre G, Crouch NP, Hotze M, Schmidt J, Strack D, Matern U, Schröder J (2000) Indole alkaloid biosynthesis in Catharanthus roseus : new enzyme activities and identification of cytochrome P450 CYP72A1 as secologanin synthase. Plant J 24:797-804

30. Ishikawa H, Colby DA, Boger DL (2008) Direct coupling of catharanthine and vindoline to provide vinblastine: total synthesis of (+)-and ent-(-)-vinblastine. J Am Chem Soc 130:420

31. Kato D, Sasaki Y, Boger DL (2010) Asymmetric total synthesis of vindoline. J Am Chem Soc 132:3685-3687

32. Kruczynsky A, Hill BT (2001) Vinflunine, the latest Vinca alkaloid in clinical development. A review of its preclinical anticancer properties. Crit Rev Oncol Hematol 40:159-173

33. Kuboyama T, Yokoshima S, Tokuyama H, Fukuyama T (2004) Stereocontrolled total synthesis of (+)-vincristine. Proc Nat Acad Sci USA 101:11966-11970

34. Kulkarni RN, Baskaran K, Chandrashekhara RS, Kumar S (1999) Inheritance of morphological traits of periwinkle mutants with modified contents and yields of leaf and root alkaloids. Plant Breed 118:71-74

35. Kulkarni RN, Bhaskaran K, Chandrashekhara RS, Khanuja SPS, Darokar MP, Shasany AK, Kumar S (2003) Dhawal-a high alkaloid producing periwinkle plant. United States Patent 6548746

36. Kumar S, Rai SP, Rai SK, Singh DV, Srivastava S, Mishra RK (2007) Plant variety of Catharanthus roseus named 'lli'. United States Patent pp 18315

37. Kumar S, Jaggi M, Taneja J, Sinha AK (2011) Cloning and characterization of two new class III peroxidase genes from Catharanthus roseus. Plant Physiol Biochem 49:404-412

38. Laflamme P, St-Pierre B, De Luca V (2001) Molecular and biochemical analysis of a Madagascar periwinkle root specific minovincinine-19-hydroxy-O-acetyltransferase. Plant Physiol 125:189-198

39. Lander ES, Botstein D (1989) Mapping Mendelian factors underlying quantitative traits using RFLP linkage maps. Genetics 121:185-199

40. Lander ES, Green P, Abrahamson J, Barlow A, Daly MJ, Lincoln SE, Newberg LA (1987) MAPMAKER: an interactive computer package for constructing primary genetic linkage maps of experimental and natural populations. Genomics 1:174-181

41. Lemenager D, Ouelhazi L, Mahroug S, Veau B, St-Pierre B, Rideau M, Aguirreolea J, Burlat V, Clastre M (2005) Purification, molecular cloning and cell-specific gene expression of the alkaloid-accumulation associated protein CrPS in Catharanthus roseus. J Exp Bot 56:1221-1228

42. Levac D, Murata J, Kim WS, De Luca V (2008) Application of carborundum abrasion for investigating the leaf epidermis: molecular cloning of Catharanthus roseus 16-hydroxytabersonine16-O-methyltransferase. Plant J 53:225-236

43. Lincoln SE, Daly M, Lander ES (1992) Constructing genetic maps with MAPMAKER/EXP. 3.0, 3rd edn. Whitehead Institute technical report, Cambridge

44. Liscombe DK, O' Connor SE (2011) A virus-induced gene silencing approach to understand alkaloid metabolism in Catharanthus roseus. Phytochemistry 72:1969-1977

45. Lorz H, Wenzel G (2005) Molecular marker systems in plant breeding and crop improvement. Springer, Berlin

46. Loyola-Vargas VM, Galas-Avalos RM, Ku-Cauich R (2007) Catharanthus biosynthetic enzymes: the road ahead. Phytochem Rev 6:307-339

47. Luijendijk TJC, van der Meijden E, Verpoorte R (1996) Involvement of strictosidine as a defensive chemical in Catharanthus roseus. J Chem Ecol 22:1355-1366

48. Ma X, Panjikar S, Koepke J, Loris E, Stöckigt J (2006) The structure of Rauvolfia serpentina strictosidine synthase is a novel six-bladed $\beta$-propeller fold in plant proteins. Plant Cell 18:907-920 
49. Mahroug S, Courdavault V, Thiersault M, St. Pierre B, Burlat V (2006) Epidermis is a pivotal site of at least four secondary metabolic pathways in Catharanthus roseus aerial organs. Planta 223:1191-1200

50. Mahroug S, Burlat V, St-Pierre B (2007) Cellular and sub-cellular organization of the monoterpenoid indole alkaloid pathway in Catharanthus roseus. Phytochem Rev 6:363-381

51. Mandal S, Maheshwari ML (1986) High pressure liquid chromatographic determination of vindoline, catharanthine, vincaleucoblastine and vincristine in periwinkle leaf. Ind J Pharm Sci 49:205-209

52. Meijer AH, Verpoorte R, Hoge JHC (1993) Regulation of enzymes and genes involved in terpenoid indole alkaloid biosynthesis in Catharanthus roseus. J Plant Res 3:145-164

53. Meisner J, Weissenberg M, Palevitch D, Aharonson N (1981) Phagodeterrency induced by leaves and leaf extracts of Catharanthus roseus in the larva of Spodoptera littoralis (Lepidoptera, Noctuidae). J Econ Entomol 74:131-135

54. Mishra P, Uniyal GC, Sharma S, Kumar S (2001) Pattern of diversity for morphological and yield related traits among the periwinkle Catharanthus roseus accessions collected from in and around Indian subcontinent. Genet Res Crop Evol 48:273-286

55. Moreno PRH, Van der Heijden R, Verpoorte R (1995) Cell and tissue cultures of Catharanthus roseus: a literature survey II. Updating from 1988 to 1993. Plant Cell Tissue Organ Cult 42:1-25

56. Murata J, De Luca V (2005) Localization of tabersonine-16hydroxylase and 16-OH tabersonine-16-O-methyltransferase to leaf epidermal cells defines them as a major site of precursor biosynthesis in the vindoline pathway in Catharanthus roseus. Plant J 44:581-594

57. Murata J, Roepke J, Gordon H, De Luca V (2008) The leaf epidermome of Catharanthus roseus reveals its biochemical specialization. Plant Cell 20:524-542

58. Nobel RL (1990) The discovery of vinca alkaloids-chemotherapeutic agents against cancer. Biochem Cell Biol 68:1344-1351

59. O'Connor SE, Maresh JJ (2006) Chemistry and biology of monoterpene indole alkaloid biosynthesis. Nat Prod Rep 23:532-547

60. Oudin A, Courtois M, Rideau M, Clastre M (2007) The iridoid pathway in Catharanthus roseus alkaloid biosynthesis. Phytochem Res 6:259-276

61. Pandey-Rai S, Luthra R, Kumar S (2003) Salt-tolerant mutants in glycophytic salinity response (GSR) genes in Catharanthus roseus. Theor Appl Genet 106:221-230

62. Pasquier E, Kavallaris M (2008) Microtubules: a dynamic target in cancer therapy. IUBMB Life 60:165-170

63. Peebles CAM, Sander GW, Hughes EH, Peacock R, Shanks JV, San K-Y (2011) The expression of 1-deoxy-D-xylulose synthase and geraniol-10-hydroxylase or anthranilate synthase increases terpenoid indole alkaloid accumulation in Catharanthus roseus hairy roots. Metabol Eng 13:234-240

64. Pelt JM (2001) Les nouveaux remedes naturels. Editions Fayard, Paris

65. Potier P (1980) Is the modified Polonovski reaction biometric? In: Philipson JD, Zenk MH (eds) Indole and biogenetically related alkaloids. Academic, London, pp 159-169

66. Roepke J, Salim V, Wu M, Thamm AM, Murata J, Ploss K, Boland W, De Luca V (2010) Vinca drug components accumulate exclusively in leaf exudates of Madagascar periwinkle. Proc Natl Acad Sci USA 107:15287-15292

67. Roytrakul S, Verpoorte R (2007) Role of vacuolar transporter proteins in plant secondary metabolism: Catharanthus roseus cell culture. Phytochem Rev 6:383-396

68. Runguphan W, Maresh JJ, O'Connor SE (2009) Silencing of tryptamine biosynthesis for production of nonnatural alkaloids in plant culture. Proc Natl Acad Sci U S A 106:13673-13678

69. Sevon N, Oksman-Caldentey K-M (2002) Agrobacterium rhizogenes-mediated transformation: root cultures as a source of alkaloids. Planta Med 68:859-868
70. Shokeen B, Sethy NR, Kumar S, Bhatia S (2007) Isolation and characterization of microsatellites for analysis of molecular variation in medicinal plant Madagascar periwinkle Catharanthus roseus (L.) G. Don. Plant Sci 172:441-451

71. Shokeen B, Choudhary S, Sethy NK, Bhatia S (2011) Development of SSR and gene-targeted markers for construction of a framework linkage map of Catharanthus roseus. Ann Bot 108:321-336

72. Shukla AK, Shasany AK, Gupta MM, Khanuja SPS (2006) Transcriptome analysis in Catharanthus roseus leaves and roots for comparative terpenoid indole alkaloid profiles. J Exp Bot 57:3921-3932

73. Singh DV, Pandey-Rai S, Srivastava S, Rai SK, Mishra RK, Kumar S (2004) Simultaneous quantification of some pharmaceutical Catharanthus roseus leaf and root terpenoid indole alkaloids and their precursors in single runs by reversed-phase liquid chromatography. JAOAC Int 87:1287-1296

74. Singh DV, Rai SK, Pandey-Rai S, Srivastava S, Mishra RK, Chaudhary S, Sharma S, Kumar S (2008) Predominance of the serpentine route in monoterpenoid indole alkaloid pathway of Catharanthus roseus. Proc Ind Natl Sci Acad 74:97-109

75. St-Pierre B, Laflamme P, Alarco AM, De Luca V (1998) The terminal $\mathrm{O}$-acetyltransferase involved in vindoline biosynthesis defines a new class of proteins responsible for coenzyme A-dependent acyl transfer. Plant J 14:703-713

76. St-Pierre B, Vazquez-Flota FA, De Luca V (1999) Multicellular compartmentation of Catharanthus roseus alkaloid biosynthesis predicts intercellular translocation of a pathway intermediate. Plant Cell 11:887-900

77. Tam A, Gotoh H, Robertson WM, Boger DL (2010) Catharanthine C16 substituent effects on the biomimetic coupling with vindoline: preparation and evaluation of a key series of vinblastine analogues. Bioorg Med Chem Lett 20:6408-6410

78. van der Heijden R, Jacobs DI, Snoeirjer W, Hallard D, Verpoorte $\mathrm{R}$ (2004) The Catharanthus roseus alkaloids: pharmacognosy and biotechnology. Curr Med Chem 11:607-628

79. Verma P, Mathur AK, Srivastava A, Mathur A (2011) Emerging trends in research on spatial and temporal organization of terpenoid indole alkaloid pathway in Catharanthus roseus: a literature update. Protoplasma. doi:10.1007/s00709-011-0291-4

80. Wang L, Zhang Y, He HP, Zhang Q, Li SF, Hao XJ (2011) Three new terpenoid indole alkaloids from Catharanthus roseus. Planta Med 7:754-758

81. Wang SC, Basten CJ, Zeng ZB (2011) Windows QTL Cartographer 2.5. Department of Statistics, North Carolina State University, Raleigh

82. Whitmer S, van der Heijden R, Verpoorte R (2002) Effect of precursor feeding on alkaloid accumulation by a tryptophan decarboxylase over-expressing transgenic cell line T22 of Catharanthus roseus. J Biotechnol 96:193-203

83. Whitmer S, Canel C, van der Heijden R, Verpoorte R (2003) Longterm instability of alkaloid production by stably transformed cell lines of Catharanthus roseus. Plant Cell Tissue Organ Cult 74:73-80

84. Yokoshima S, Ueda T, Kobayashi S, Sato A, Kuboyama T, Tokuyama H, Fukuyama T (2002) Sterocontrolled total synthesis of (+)-vinblastine. J Am Chem Soc 124:2137-2139

85. Zarate R, Verpoorte R (2007) Strategies for the genetic modification of the medicinal plant Catharanthus roseus (L.) G. Don. Phytochem Rev 6:475-491

86. Zeng ZB (1994) Precision mapping of quantitative trait loci. Genetics 136:1457-1468

87. Zhao J, Verpoorte R (2007) Manipulating indole alkaloid production by Catharanthus roseus cell cultures in bioreactors: from biochemical processing to metabolic engineering. Phytochem Rev 6:435-457 